\title{
Comparison of the open-closed field line boundary location inferred using IMAGE-FUV SI12 images and EISCAT radar observations
}

\author{
B. Hubert ${ }^{1}$, A. T. Aikio ${ }^{2}$, O. Amm ${ }^{3}$, T. Pitkänen ${ }^{2}$, K. Kauristie ${ }^{3}$, S. E. Milan ${ }^{4}$, S. W. H. Cowley ${ }^{4}$, and J.-C. Gérard ${ }^{1}$ \\ ${ }^{1}$ Laboratory for Planetary and Atmospheric Physics, University of Liège, Liège, Belgium \\ ${ }^{2}$ Department of Physics, University of Oulu, Oulu, Finland \\ ${ }^{3}$ Space Physics Group, Finnish Meteorological Institute, Helsinki, Finland \\ ${ }^{4}$ Department of Physics and Astronomy, University of Leicester, Leicester, UK
}

Received: 24 June 2009 - Revised: 29 January 2010 - Accepted: 19 March 2010 - Published: 1 April 2010

\begin{abstract}
We compare the location of the polar cap boundary (PCB) determined using two different techniques, and use them as proxies for the open-closed field line boundary (OCB). Electron temperatures from observations of the EISCAT radar facility are used to estimate the latitude of the PCB along the meridian of the EISCAT VHF beam. The second method utilizes global images of proton aurora obtained by the IMAGE satellite FUV SI12 instrument. These methods are applied to three different intervals. In two events, the agreement between the methods is good and the mean of the difference is within the resolution of the observations. In a third event, the PCB estimated from EISCAT data is located several degrees poleward of that obtained from the IMAGE FUV SI12 instrument. Comparison of the reconnection electric field estimated from the two methods shows that highresolution measurements both in time and space are needed to capture the variations in reconnection electric field during substorm expansion. In addition to the two techniques introduced above to determine the PCB location, we also use a search for the location of the reversal of the east-west component of the equivalent current known as the magnetic convection reversal boundary (MCRB). The MCRB from the MIRACLE magnetometer chain mainly follows the motion of the polar cap boundary during different substorm phases, but differences arise near the Harang discontinuity.
\end{abstract}

Keywords. Magnetospheric physics (Magnetopause, cusp, and boundary layers; Storms and substorms; Instruments and techniques)

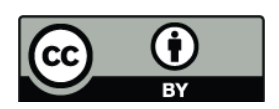

Correspondence to: B. Hubert (b.hubert@ulg.ac.be)

\section{Introduction}

Techniques which allow the identification of the the polar cap boundary (PCB), the boundary that separates the ionospheric polar cap from the auroral oval, are used as a proxy for the open-closed field line boundary (OCB) to analyze the cycle of accumulation and release of open magnetic flux and energy by the magnetosphere in its interaction with the solar wind. Several techniques have been considered, based on observations of the auroral emissions (Blanchard et al., 1995; Wild et al., 2004; Hubert et al., 2006a; Boakes et al., 2008), in situ particle detection (Newell et al., 1991; Blanchard et al., 1997), analysis of radar backscatter from the moving ionospheric plasma (Milan et al. 2003, and references therein; Chisham et al., 2005), or a combination of in situ particle measurements and radar backscatter analysis (Chisham et al., 2004). Estimates of the electron temperature were also used by Østgaard et al. (2005) and Aikio et al. (2006) to determine the location of the polar cap boundary.

Newell et al. (1991) characterized the properties of the precipitating auroral particles as measured using the DMSP satellites to estimate the location of the PCB. Blanchard et al. (1995) used ground based measurements of the auroral emission from metastable oxygen $\mathrm{O}\left({ }^{1} \mathrm{D}\right)$ at $630 \mathrm{~nm}$ to estimate the location of the PCB and compared it with in situ measurements of the precipitating particles using the DMSP satellites. Hubert et al. (2006a) used remote sensing of the proton aurora at all MLT sectors using the Spectrographic Imager at $121.8 \mathrm{~nm}$ (SI12) of the Far Ultraviolet (FUV) experiment onboard the Imager for Magnetopause to Aurora Global Exploration (IMAGE) satellite (Mende et al., 2000a, b), and estimated the location of the polar cap boundary as well as the flux opening and closure reconnection voltages. Wild et al. (2005) and Boakes et al. (2008) used remote sensing of

Published by Copernicus Publications on behalf of the European Geosciences Union. 
the electron-dominated auroral emissions, which can be obtained using the Spectrographic Imager at $135.6 \mathrm{~nm}$ (SI13) and the Wide Band Imaging Camera (WIC) instruments of the IMAGE-FUV experiment to estimate the location of the polar cap boundary in MLT sectors uncontaminated by the dayglow. Chisham et al. $(2005,2008)$ showed from a statistical standpoint that the spectral width boundary (SWB), the boundary between broad and narrow backscatter echoes, is a reliable proxy for the open/closed boundary close to noon and midnight. The electron temperature enhancement in the nightside ionosphere has also been used as a proxy for the OCB by Østgaard et al. (2005), who combined FUV images of the electron aurora with electron temperature measurements by the EISCAT radar. This method was extended by Aikio et al. (2006) as discussed in more detail in Sect. 2.

Knowledge of the location and motion of the OCB (generally through a PCB-based proxy), combined with a determination of the ionospheric electric field using e.g. SuperDARN observations, then allows one to estimate the electric field in the moving frame of reference of the boundary, and hence the dayside and nightside reconnection rates (Siscoe and Huang, 1985; Grocott et al., 2002; Milan et al., 2003, 2004; Hubert et al., 2006a, and references therein). Chisham et al. (2004) measured the dayside reconnection rate during an interval of northward IMF combining SuperDARN and DMSP data. Blanchard et al. (1996, 1997a) developed a method to determine the local nightside reconnection rate using ground based measurements of the emission of metastable oxygen $\mathrm{O}\left({ }^{1} \mathrm{D}\right)$ at $630 \mathrm{~nm}$ combined with radar measurement of the ionospheric flow, and applied it to the study of several substorms (Blanchard et al., 1997b). They found that the nightside reconnection rate increases shortly after substorm onset. Hubert et al. (2006a) analyzed several substorm intervals using SI12 and SuperDARN data and found that pseudobreakups can close magnetic flux prior to substorm onset, while the closure voltage reaches its maximum intensity shortly after onset. They also found that "poleward boundary intensifications" (PBIs) are related to flux closure, while Pitkänen et al. (2009a, b) showed one-toone correlation between PBIs and local reconnection electric field enhancements. Hubert et al. (2006b) used the method of Hubert et al. (2006a) to show that the compression of the magnetotail by solar wind dynamic pressure pulses can directly drive flux closure. Using the same method, Hubert et al. (2007) analyzed the relation between magnetic flux closure and auroral streamers, while Hubert et al. (2008) studied the relation between magnetic reconnection and sawtooth sequences. Estimates of the magnetotail reconnection rate at one point of the boundary have shown that the reconnection electric field varies on time scales of minutes to tens of minutes (e.g. Østgaard et al., 2005; Pitkänen et al., 2009a, b).

Identifying the location of the OCB remains a challenge whatever the technique used. The main difficulty comes from the fact that the boundary itself is not directly observable, involving a change in the topology of the magnetic field lines linking differing regions of space. This can only be inferred from the resulting differences in the plasma populations, as observed through auroral emissions, heating, direct detection of particles etc., so that one rather identifies the polar cap boundary (PCB), used as a proxy for the OCB. It also follows that experimentally the location of the OCB is a somewhat fuzzy concept, because it may depend on the properties of the particles used to detect the boundary. It is thus valuable to compare different methods used to identify the boundary location. In the present study, we compare the location of the PCB determined from two different methods, global imaging of the proton aurora, and ionospheric electron temperature determined from radar measurements by the EISCAT facility. We also compare the location of these boundaries with a third boundary: the magnetic convection reversal boundary (MCRB), which is not expected to always follow the PCB, and thus nor the OCB.

\section{Data and methods}

The first method we use relies on global observations of the proton aurora from the Spectrographic Imager at $121.8 \mathrm{~nm}$ (SI12) of the Far Ultraviolet (FUV) experiment onboard the IMAGE spacecraft (Mende et al., 2000b). This instrument is sensitive to Doppler-shifted Lyman- $\alpha$ photons that are emitted by precipitating auroral protons that have captured an electron, thus becoming a fast excited hydrogen atom. The SI12 images are not sensitive to the dayglow, and both the nightside and dayside aurora can be sensed, even in summer. The background of the image is fitted with a 2-D polynomial and carefully removed, avoiding the inclusion of auroral pixels in the fitting process. The residual noise left in the image after subtraction of the background is analyzed statistically to determine the threshold (empirically fixed to 1.15 times the median of the noise) to use to zero the auroral signal. A series of median filtering of different widths and recursive searches for significant signal is also used now to identify the aurora, which was not employed by Hubert et al. (2006a). Median filtering is known to efficiently remove the "salt-andpepper noise" from images. We apply median filtering to the residual image using a width of $5 \times 5$ and $7 \times 7$ pixels, the SI12 image being a square of $128 \times 128$ pixels. We compare the results to identify what pixels of small intensity can be considered as auroral signal rather than noise, avoiding inclusion of isolated small patches made of a few contiguous dim pixels. The result is a nonsystematic slight broadening of the determined auroral oval obtained at the expense of a larger noise in the estimated boundary location. The poleward boundary of the aurora, i.e. the PCB, is identified and fitted with a Fourier series such that the radius of the boundary projected in the (magnetic) equatorial plane is fitted with the function

$r=\sum_{n}\left(a_{n} \cos (n \varphi)+b_{n} \sin (n \varphi)\right)+c$ 
where parameters $a_{n}, b_{n}$ and $c$ are to be fitted and $\varphi$ is the magnetic local time expressed in radians.

This fitted PCB is taken as a proxy for the OCB. MLT sectors in which the aurora is too dim to be detected in SI12 images are filled by interpolation, and these sectors are assigned a low weight when fitting the boundary with a Fourier series. This prevents the fitted series from producing artificial unrealistic oscillations in those MLT sectors in which the boundary location is not constrained by the observations. From a statistical standpoint, this boundary corresponds well to the OCB inferred from DMSP spacecraft particle observations. We conducted a comparison between 656 coincident determinations of the OCB using DMSP data and SI12 images that occurred between June 2000 and July 2001 following the same procedure as Hubert et al. (2006a) concerning the DMSP "boc" boundary (i.e. the open-closed field line boundary deduced from the classification of particle regimes using the DMSP in situ measurements). The comparison shows that, on average, the boundaries differ by $0.23 \pm 0.10 \mathrm{DEG}$ MLAT, with a standard deviation of $\sim 2.65$ DEG MLAT, the DMSP boundary being generally poleward of the SI12 boundary. This difference is below the resolution of the SI12 instrument ( $\sim 1$ DEG MLAT). This result is better than that of the previous comparison of Hubert et al. (2006a), suggesting that the slight modifications of the method that we have introduced have improved its reliability (at least in terms of statistical agreement with the boundary determined from the DMSP particle measurements), so that no systematic correction of the boundary location is applied in the results presented here.

The second method used in this paper to estimate the PCB location utilizes EISCAT radar facility observations of the ionospheric electron temperature (Aikio et al., 2006). The energy flux of electron precipitation inside the oval is typically larger than that of the polar rain precipitating in the polar cap, resulting in an elevated electron temperature $T_{\mathrm{e}}$ within the oval. Low-elevation VHF radar observations from Tromso (corrected geomagnetic coordinates: $66.6^{\circ} \mathrm{MLAT}$, $103^{\circ} \mathrm{MLON}$ ) in the poleward direction are used to identify the most poleward location that has higher $T_{\mathrm{e}}$ than at the corresponding altitude within the polar cap, measured by the field-aligned EISCAT Svalbard radar (ESR) at Longyearbyen. This estimate of the PCB location is taken as a proxy for the OCB location.

The reconnection electric field can be calculated from EISCAT VHF low-elevation dual-beam measurements as follows (for details, see Pitkänen et al., 2009a, b). In dual beam working mode, the radar uses two nearly horizontal beams that point in different directions, and the PCB location is determined for the two beams separately as explained above. The typical difference in the azimuthal directions of the beams is $17^{\circ}$. Hence one gets the orientation of the PCB. Line-of-sight plasma velocities along the two beams in the Fregion are used to calculate the horizontal plasma $\boldsymbol{E} \times \boldsymbol{B} \mathrm{drift}$ velocity component perpendicular to the PCB. This plasma velocity together with the calculated PCB velocity gives the ionospheric value of the reconnection electric field.

The third technique used in this paper is a search for the location of the reversal of the east-west component of the equivalent current (EQJ), known as the magnetic convection reversal boundary (MCRB), determined using magnetometer data from the MIRACLE network in Scandinavia. By itself, this is not a determination of the PCB location, nor of the OCB location. However, this boundary depends on the ionospheric current system and on the ionization produced by the auroral precipitation, so that the motion of this boundary can be expected to mimic that of the OCB, and in some circumstances, the boundaries may well match each other (Amm et al., 2003; Aikio et al., 2006, 2008).

In the following sections, we analyze three intervals for which these data are available, namely $17: 30$ to $23: 15$ UT on 22 September 2001, 20:30 UT on 17 February to 00:30 UT on 18 February 2002, and 20:20 to 22:00 UT on 7 December 2000.

\section{$3 \quad 22$ September 2001}

On 22 September 2001, FUV observations are available until 23:25 UT, when the IMAGE spacecraft approached its perigee and the northern polar region was no longer observed. The EISCAT PCB estimates are made during the interval 18:15-22:00 UT (magnetic midnight at Tromso is at 21:25 UT). Between 17:30 and 18:00 UT the auroral activity observed with the IMAGE-FUV imagers is decaying. Figure 1a shows the aurora observed with the WIC imager onboard the IMAGE satellite. Brightenings reminiscent of a sequence of weak pseudobreakups are seen after 18:30 UT, and a weak auroral brightening is seen at $\sim 18: 57 \mathrm{UT}$, followed by the slow formation of an auroral bulge of moderate extent. A second weak brightening is seen at 19:23-19:25 UT also followed by a moderate poleward retraction of the oval, with ongoing activity until a third brightening is seen at 20:02 UT. The latter is followed by the formation of a larger bulge, and preceded by a very weak brightening and poleward motion of the oval after 19:46 UT (not shown). Magnetometer data (not shown) from the MIRACLE International Monitor for Auroral Geomagnetic Effects (IMAGE) Scandinavian chain of magnetometers (not to be confused with the IMAGE satellite) suggest little activity starting shortly after 19:50 UT. The AE, AU and AL indices indicate an increased activity after 06:00 UT and a strong activity after 11:00 UT on that day (Fig. 1b), which progressively fades after 18:00 UT. As the AE index was higher than $200 \mathrm{nT}$ and the AL index was fairly stable for a long period of time (after 12:30 UT), this interval is reminescent of a steady magnetic convection event (Mc Williams et al., 2008). The interval considered in our study thus appears to be representative of the end of a rather long period of ongoing active conditions and could be seen as a sequence of two moderate substorms or more likely 

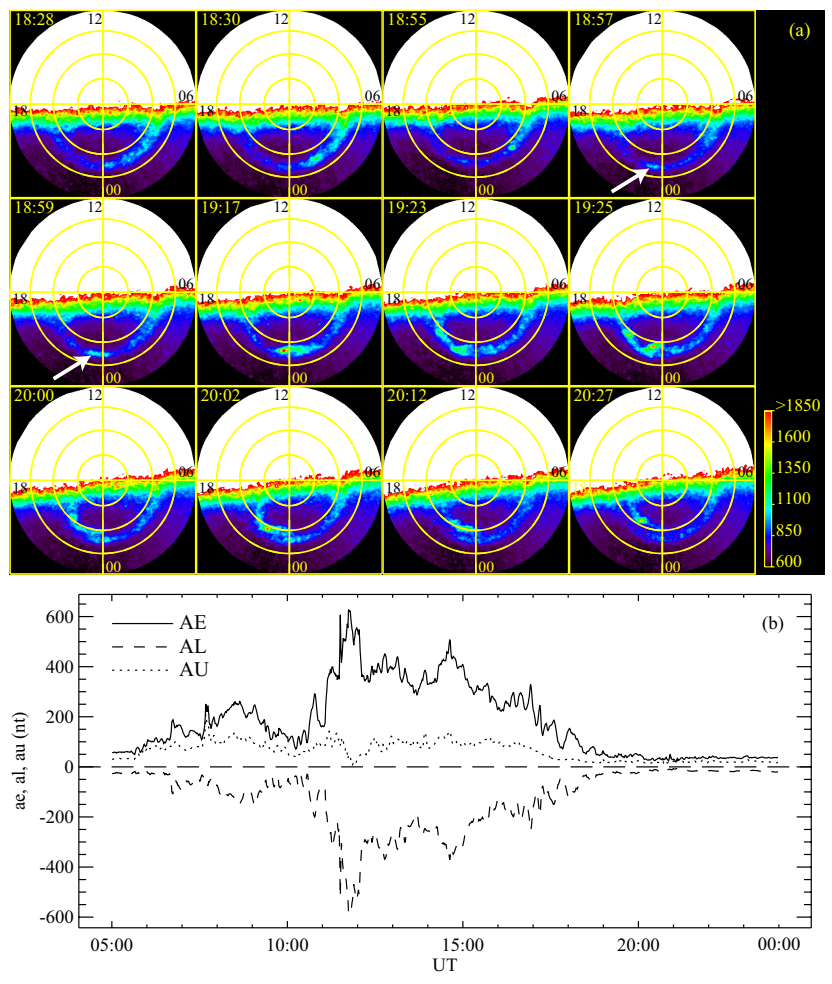

Fig. 1. (a) Polar view of the WIC count rate obtained on 22 September 2001, in magnetic coordinates (noon at top, concentric circles every 10 Deg MLAT). The bright dayglow appears as white in the upper part of each image. The white arrows show the brightening at 18:57 UT and its evolution at 18:59 UT. (b) Auroral AE, AL and AU indices recorded on 22 September 2001.

pseudobreakups (as they are followed by the formation of a restricted auroral bulge only), followed by a more intense, though still not violent, expansion phase with onset around 20:00 UT, the three events slightly overlapping each other. However, the absence of a strong expansion phase, which would result from vigorous flux closure in the tail, is indeed more compatible with the active conditions of an SMC, as deduced from the $\mathrm{AE}$ and $\mathrm{AL}$ values observed on that day. The observed brightenings could then be considered as the usual auroral features of SMCs, as (transient) brightenings are often observed during SMCs (Sergeev et al., 2006). These brightenings could take place because the balance between flux opening on the dayside and flux closure on the nightside do not exactly compensate each other, so that the magnetosphere still accumulates open flux at a level slightly above its possible steady state, that has to be eventually closed some time later.

Figure 2a presents the SI12 count rate along the meridian crossing the location of the EISCAT VHF beam on 22 September 2001. The dotted lines represent the PCB deduced from the SI12 observations and the solid line the boundary deduced from the EISCAT data. Figure $2 b$ shows the location of the PCBs during the interval with simulta-
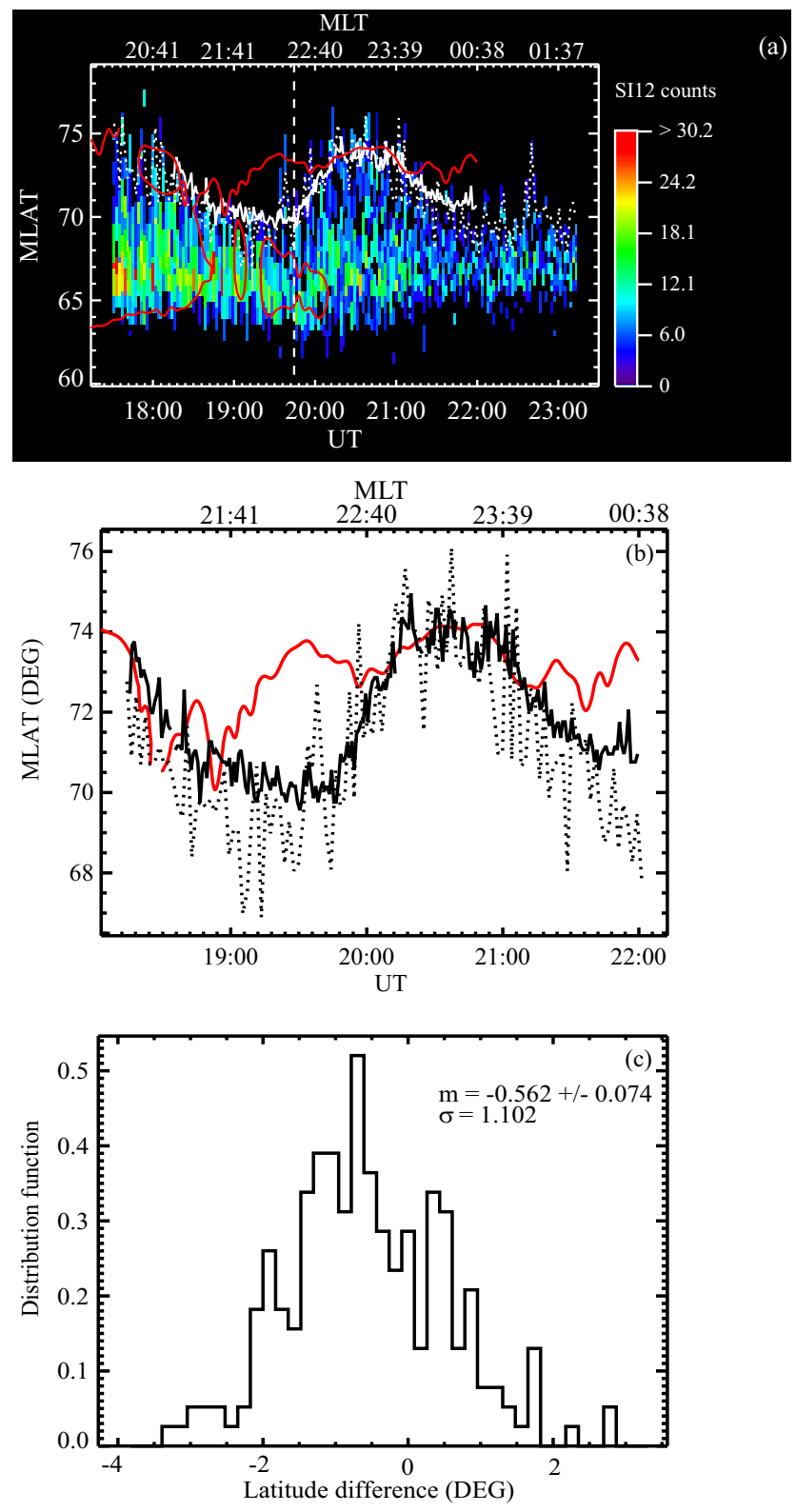

Fig. 2. (a) Keogram of SI12 counts along the meridian corresponding to the EISCAT field of view on 22 September 2001. The overlaid white solid line represents the location of the EISCAT PCB, the dotted lines show the SI12 PCB, and the red solid lines represent the MCRBs as determined using the MIRACLE magnetometer data. The vertical dashed line indicates the beginning of net flux closure. (b) Blowup of the polar cap boundaries determined during the interval with simultaneous EISCAT observations, with the same line conventions as in panel (a). (c) Distribution function of the difference between the latitude of the SI12 and EISCAT PCB.

neous EISCAT observations. The two boundaries are consistent, and generally depart from each other by less than $\sim 1.5^{\circ}$ MLAT. Figure $2 \mathrm{c}$ shows the distribution of the differences between the EISCAT and SI12 boundaries. The size of the bins used to construct the distribution is chosen 
such that, in the interval $(m-\sigma, m+\sigma)$, the number of data points per bin is equal to 12 on average. The average difference is $m \sim-0.56 \pm 0.07$ DEG MLAT, and the standard deviation of the distribution is $\sigma \sim 1.10$ DEG MLAT. (The average value of the absolute difference is $1.02 \pm 0.05$ DEG MLAT.) The EISCAT boundary is thus located slightly poleward of the SI12 boundary, but by an amount nearly equal to the SI12 resolution on average. The EISCAT and SI12 polar cap boundaries show the same equatorward motion before 19:50 UT, possibly similar to the substorm growth phase, and the same poleward retraction of the boundary as magnetic flux is closed during the (weak) expansion-like phase after 20:02 UT. Before the main poleward motion of the boundary (i.e. before 19:50 UT), the average difference between EISCAT and SI12 is $m \sim-0.84 \pm 0.11$ DEG MLAT, with a standard deviation $\sigma \sim 1.04$ DEG MLAT. During the poleward motion of the boundary between 19:50 and 20:20 UT, an interval of flux closure, we find $m \sim 0.35 \pm 0.17$ DEG MLAT and $\sigma \sim 0.17$ DEG MLAT. Between 20:20 and 21:00 UT, the boundary location is fairly stable, suggesting a recovery phase. For that part of the interval, we have an average difference $m \sim-0.16 \pm 0.18$ DEG MLAT and $\sigma \sim 1.09$ DEG MLAT. After 21:00 UT, the boundary moves back equatorward as the magnetosphere starts accumulating open flux again. The magnetosphere completes recovering, and possibly starts the growth phase of the next substorm, and we find $m \sim-0.81 \pm 0.13$ DEG MLAT, with $\sigma \sim 1.01$ DEG MLAT.

Nine DMSP passes are also available at different MLT sectors between 17:45 and 23:20 UT from which the PCB may be identified, allowing a comparison with the SI12 observations. On average, the SI12 boundary is found $\sim 1.5$ DEG MLAT equatorward of the DMSP boundary.

The red solid lines in Fig. 1a and b show the MCRB locations as determined from the MIRACLE data. Throughout this paper, a suitable time smoothing is applied to the EQJ maps in order to filter out the high frequency variations of the MCRB location. Before the intensification at 18:57 UT, the polewardmost MCRB and the PCB determined from SI12 data are located close to each other. After that until 20:15 UT the Harang discontinuity region is seen (the zero line descends in latitude within the region of aurora). During this time, the poleward boundary of the westward electrojet (the upwardmost zero line) is located well poleward of the PCB determined by both EISCAT and SI12, by some $\sim 4$ DEG at worst. Only after 20:15 UT do the MCRB and the PCB roughly coincide. Similar behaviour within the Harang region is shown in Pitkänen et al. (2009a, b). Interestingly, a part of the equivalent current is found to flow in a region threaded by open field lines.

\section{February 2002}

On 17 February 2002, IMAGE-FUV SI12 observations can be used to estimate the PCB location from 20:30 UT until
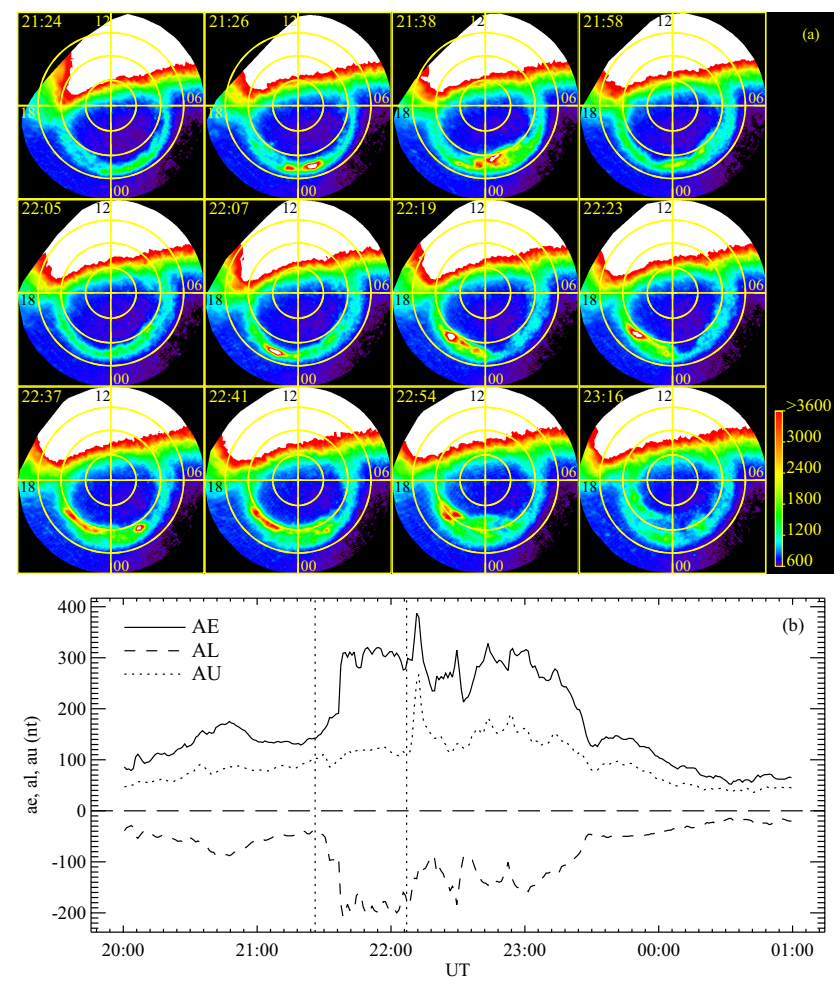

Fig. 3. (a) Polar view of the WIC count rate obtained on 17 February 2002, in magnetic coordinates (noon at top, concentric circles every 10 Deg MLAT). The bright dayglow appears as white in the upper part of each image. (b) Auroral AE, AL and AU indices recorded on 17 and 18 February 2002. The vertical dotted lines indicate substorm onsets.

00:30 UT the next day. The EISCAT PCB was determined between 22:31 and 22:58 UT (midnight MLT sector) and the MCRB was determined between 22:00 UT and midnight. The auroral activity is weak at the beginning of the interval. Pseudobreakups are then observed with the IMAGEFUV imagers after 21:00 UT, and an expansion onset takes place at 22:07 UT followed by the development of an auroral bulge as seen in particular in the WIC images shown in Fig. 3a. Note that the very slow time development of this substorm expansion is somewhat unusual, maybe because it takes place at the end of another substorm with onset at 21:26 UT. Indeed, the AE, AL and AU indices do not allow a clear identification of the onset at 22:07 UT despite the sharp $\mathrm{AU}$ increase between 22:07 and 22:12, because the activity remains high after 21:26 UT (Fig. 3b). The onset at 22:07 UT occurs as the recovery phase of the previous substorm is not completely finished. Indeed, observations from the IMAGE magnetometer chain (not shown) indicate significant continued activity between 21:20 and 23:00 UT. We also compute the opening and closure reconnection voltages combining the SI12 and SuperDARN observations. This shows that the flux closure rate grows progressively after onset. It changes from $\sim 50 \mathrm{kV}$ to $\sim 90 \mathrm{kV}$ after $\sim 10 \mathrm{~min}$, and then remains larger 

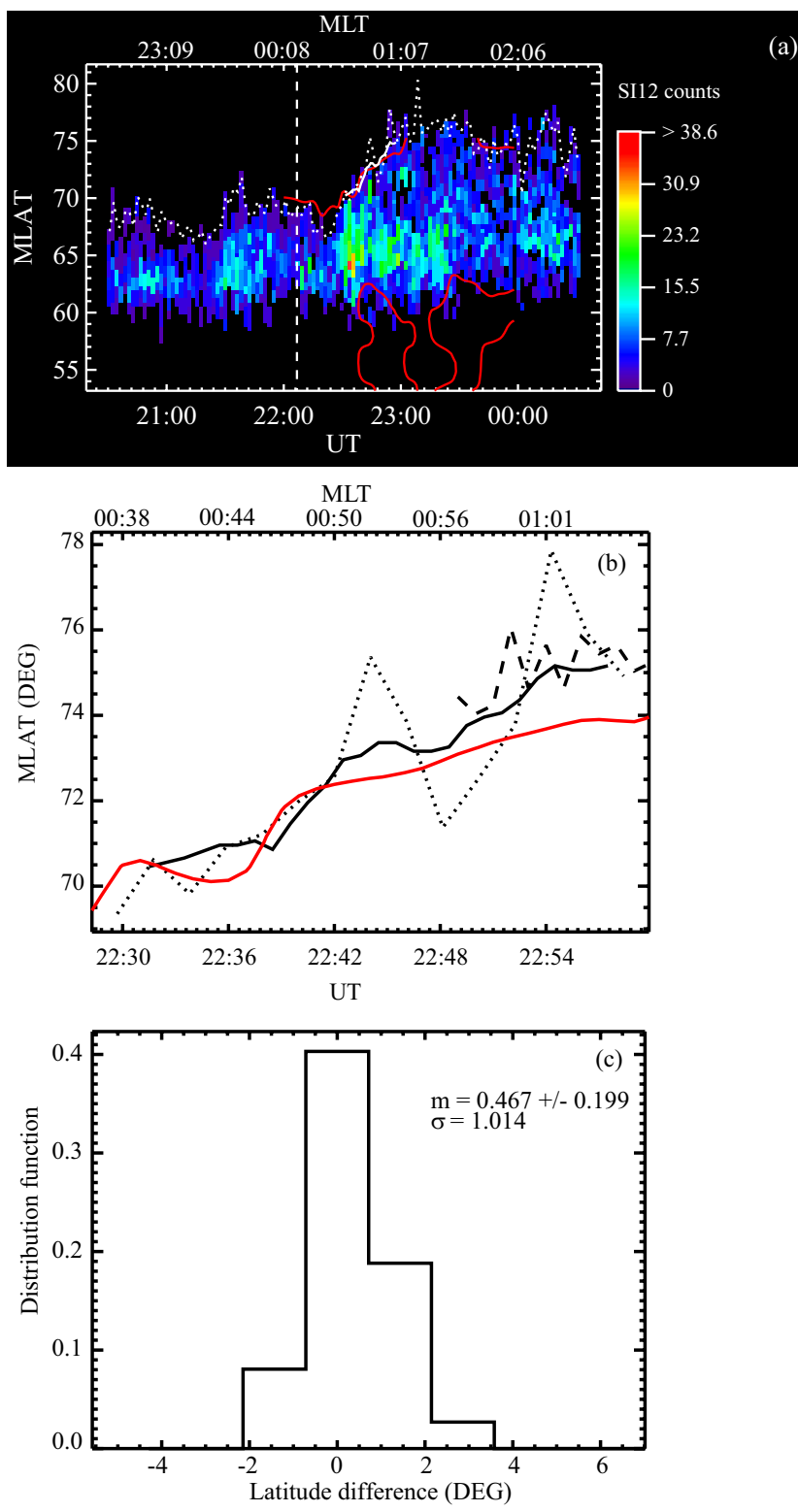

Fig. 4. Same as Fig. 2 for 17 February 2002, with, in addition, the polar cap boundary deduced from observations of the OI $630 \mathrm{~nm}$ emission at Longyearbyen represented by the dashed line in panel (b).

than $90 \mathrm{kV}$ for $\sim 40 \mathrm{~min}$, consistent with the FUV imaging that shows poleward retraction of the polar cap boundary during this interval. This is an unusual time scale for a substorm expansion phase.

Figure 4 presents results in the same format as Fig. 2, with in addition the polar boundary of the OI $630 \mathrm{~nm}$ auroral emission (see next paragraph). The EISCAT PCB and the SI12 $\mathrm{PCB}$ are both available while the polar cap boundary retracts poleward, i.e. during the intense flux closure of the expansion phase. They correspond well to each other with an average difference $m \sim 0.47 \pm 0.20$ DEG MLAT, and a standard deviation of $\sigma \sim 1.01$ DEG MLAT (Fig. 4c). (The average absolute difference is $0.87 \pm 0.14$ DEG MLAT). During this interval, the average SI12 boundary location is thus located somewhat poleward of the EISCAT boundary, opposite to the situation in Fig. 2, but along the same lines as is found between 19:50 and 20:20 UT on 22 September 2001, i.e. during active conditions. However, the SI12 PCB shows rather large oscillations which are not believed to be real, but produced by the Fourier analysis method used (oscillations are also present in the 22 September 2001 event), that tends to reproduce noisy variations of the SI12 boundary versus MLT. Time smoothing, generally applied for the computation of reconnection voltages for example, will reduce these oscillations.

For comparison, three coincidental DMSP passes were found between 21:40 UT on 17 February and 00:30 UT on 18 February, from which the OCB can be identified. On average, the SI12 boundary was found to be $\sim 0.98$ DEG MLAT poleward of the DMSP boundary. During part of the interval, the PCB location could also be determined using observations of the OI $630 \mathrm{~nm}$ emission from the Longyearbyen all-sky camera station (Blanchard et al., 1995). As shown in Fig. 4b, the $630 \mathrm{~nm}$ boundary corresponds well to the EISCAT boundary, which may be expected since the OI $630 \mathrm{~nm}$ emission is also excited by the electron aurora. The contour plot of the MCRB deduced from the MIRACLE magnetometer data, represented by the red solid lines in Fig. 3a and b, also corresponds well to the SI12 and EISCAT polar cap boundaries. (Between $\sim 23: 00$ and $\sim 23: 50 \mathrm{UT}$, the MCRB is located outside of the area covered by the MIRACLE data.) The three boundaries consistently capture the poleward motion expected during the substorm expansion phase.

The location of the open-closed field line boundary is generally not investigated for its own sake, but rather in order to estimate magnetic reconnection voltages, thus setting the observations in a magnetospheric context. The estimated voltages not only depend on the boundary location and motion, but also on the estimated ionospheric electric field. This last dependance can be an important source of uncertainty, at least locally, in circumstances in which the details of the ionospheric electric field are poorly known, in addition to the uncertainty affecting the estimated OCB location itself. The reconnection electric field $E_{\text {rec }}$ can be calculated from the EISCAT measurements during this interval because of the dual-beam mode, giving a high resolution knowledge of the ionospheric electric field. The combination of the SI12 boundary location and the plasma velocity measured by the SuperDARN radar also allows us to determine the reconnection electric field along the whole OCB boundary (Hubert et al., 2006a). The computation of the velocity of the SI12 boundary requires time smoothing, and sliding averages over 12 min have been used. Figure 5 shows the reconnection electric field deduced from the EISCAT observations and that obtained by combining the SI12 and SuperDARN observations at the longitude of the EISCAT measurements. No 


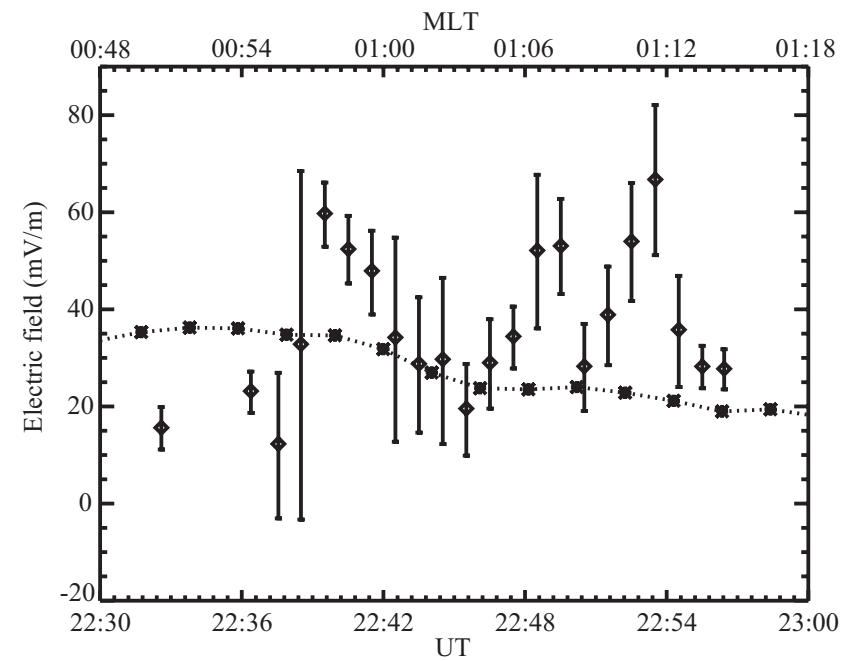

Fig. 5. Reconnection electric field at the OCB determined using EISCAT observations (diamonds) and SI12 and SuperDARN data (stars) on 17 February 2002.

EISCAT data were available at the time of the onset, and we cannot compare the electric field prior to and after the onset with a high resolution. The EISCAT data indicate that $E_{\text {rec }}$ is about $15 \mathrm{mV} \mathrm{m}^{-1}$ at 22:32 UT, while 5 min later it suddenly increased to $60 \mathrm{mV} \mathrm{m}^{-1}$, and then slowly decayed until 22:45 UT. Within the same time interval, the SI12 estimate shows a very smooth behaviour with a value of $35 \mathrm{mV} \mathrm{m}^{-1}$, and with a slow decay towards the end. The average values of both methods are very close to each other during this part of the interval, although only Eiscat can captured the detailed variations. After 22:46 UT, two short-lived (about 5 and $6 \mathrm{~min}$ ) intensifications in $E_{\mathrm{rec}}$ were observed by EISCAT, but $E_{\text {rec }}$ from SI12 is clearly lower than the values from EISCAT. The difference in $E_{\text {rec }}$ during the first part of the interval can be explained by the averaging method used for the SI12 data, but for the latter part of the interval other factors must contribute. There was no SuperDARN coverage over Scandinavia at that time, so the ionospheric plasma velocity was reconstructed using a statistical model and interpolation (Ruohoniemi and Greenwald, 1996; Ruohoniemi and Baker, 1998) that can miss the local details of the ionospheric convection and thus of the associated electric field. In this case, the contribution of the SuperDARN-based model plasma velocity to the reconnection electric field is small compared to the contribution of the OCB motion obtained from the SI12 instrument. The latter is the main contributing factor (not shown) gives an average value of about $23 \mathrm{mV} \mathrm{m}^{-1}$ between 22:30 and 23:00 UT, while the estimated ionospheric electric field produces only a few additional $\mathrm{mV} \mathrm{m}^{-1}$,s, both estimated contributions varying rather smoothly. On the other hand, the EISCAT radar measures both plasma and boundary motions with a high temporal $(1 \mathrm{~min})$ and spatial resolution. The discrepancy between the two methods during the later
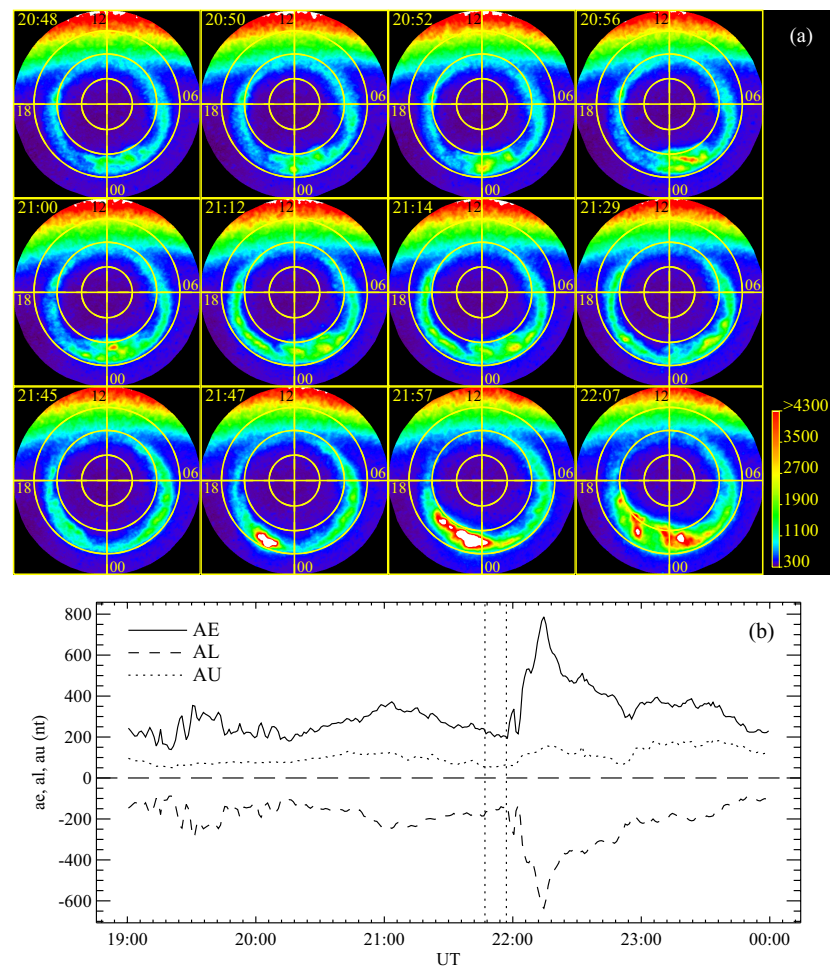

Fig. 6. (a) Polar view of the WIC count rate obtained on 7 December 2000, in magnetic coordinates (noon at top, concentric circles every 10 Deg MLAT). (b) Auroral AE, AL and AU indices recorded on 7 December 2000. The vertical dotted lines indicate the auroral brightenings observed at 21:47 and 21:57 UT.

part of the interval seems clearly related to the lack of SuperDARN data coverage over Scandinavia, rather than to a difference in the estimated OCB location.

\section{December 2000}

On 7 December 2000, IMAGE-FUV data offer a full coverage of the northern oval after 18:20 UT. Our study of this interval differs form that of Østgaard et al. (2005) who compared the WIC images with the data from the EISCAT ESR radar, located in the Svalbard archipelago. These images show a series of pseudobreakups or a minor expansion phase that take place between 20:30 and 21:16 UT. Such a pseudobreakup takes place at 20:50 UT, as shown in Fig. 6, for example. A strong substorm expansion phase then develops after 21:47 UT particularly after the auroral brightening seen at 21:57 UT, as it also appears in the AE and AL indices (Fig. 6). A large part of the auroral brightening develops over Scandinavia, allowing us to analyze it with the EISCAT radar system and the MIRACLE magnetometer network. MIRACLE data are available throughout the interval, whereas the PCB can be determined using the EISCAT radar system between 20:55 and 21:32 UT (premidnight MLT sector), when 

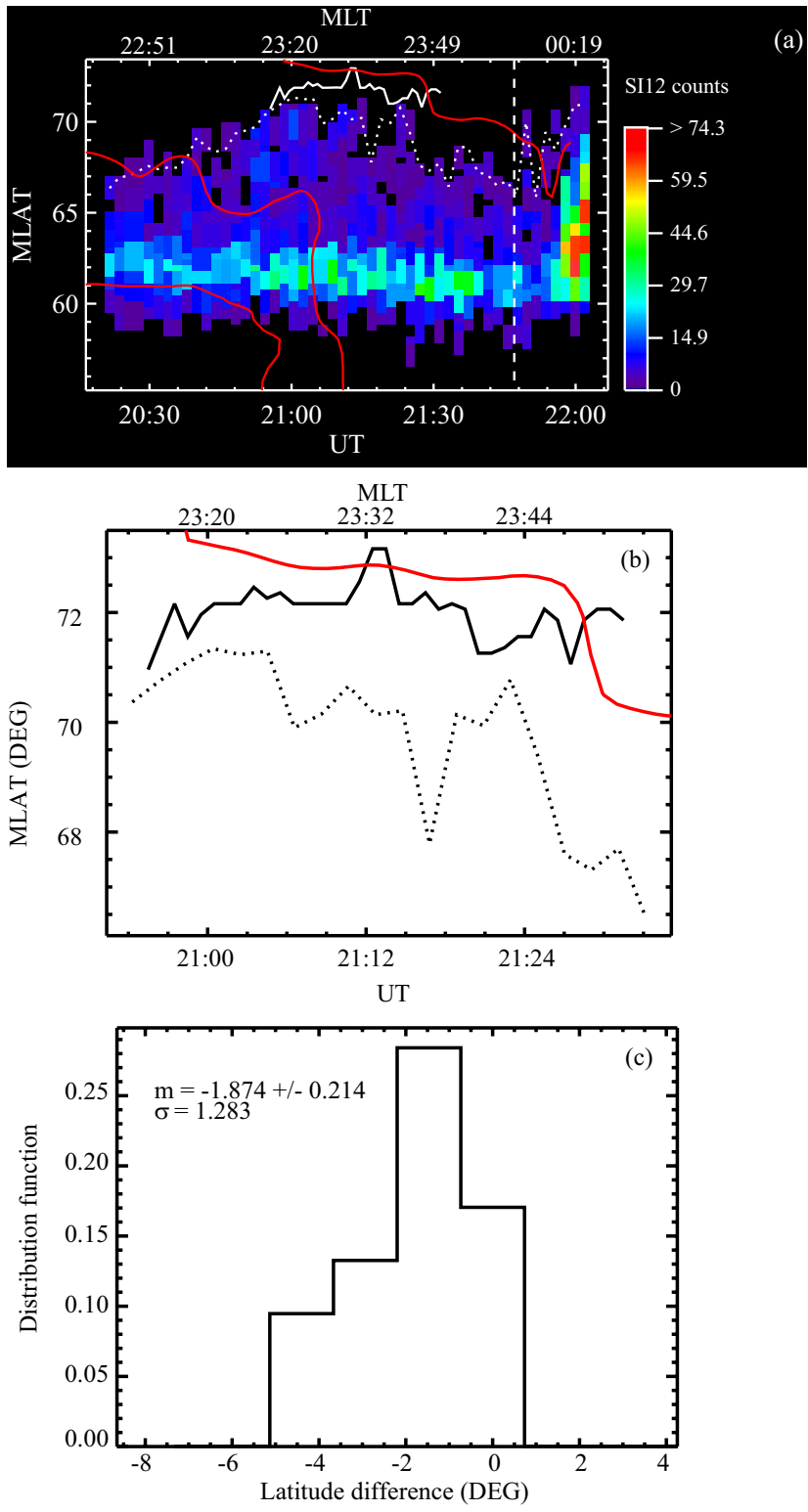

Fig. 7. Same as Fig. 2 for 7 December 2000.

the poleward boundary of the auroral oval is fairly stable at high latitude, so that this situation is likely representative of the recovery phase.

Figure 7a shows the SI12 count rate along the meridian corresponding to the EISCAT radar field of view in the interval 20:20-22:02 UT on 7 December 2000. The general trends of the EISCAT and SI12 PCBs, also shown in Fig. 7b, are roughly comparable, although it is found that the latitude of the SI12 boundary decreases with time faster than that determined by EISCAT, with an average discrepancy of $m \sim-1.87 \pm 0.2$ DEG MLAT. The standard deviation of the latitude difference is $\sigma \sim 1.28$ DEG MLAT (Fig. 7c), but differences up to $\sim 5$ DEG MLAT can be found. The boundary deduced from the electron temperature using EISCAT in this case is thus found to be significantly poleward of that of the proton precipitation detected by SI12.

Prior to 20:40 UT, the SI12 PCB and the MCRB match each other with an accuracy better than $1^{\circ}$ during more than 10 min (Fig. 7a). A difference of $1^{\circ}$ is comparable with the SI12 resolution. After that, the Harang discontinuity appears in the MLT sector studied (the red zero line in the middle of the oval in Fig. 5a). The most poleward zero line indicating the poleward boundary of the westward EQJ is located up to $1^{\circ}$ MLAT poleward of the EISCAT PCB, which is located several degrees poleward of the SI12 PCB, suggesting that the westward current is present in regions threaded by open field lines during a part of this interval as well. After 21:30 UT the MCRB and SI12 PCB both drift equatorward, as open magnetic flux is accumulated. This accumulation is relaxed in an expansion phase that develops after 21:47 UT as mentioned earlier.

The resolution of the SI12 instrument projected on the planet is $\sim 1^{\circ}$ MLAT. Moreover, a slight uncertainty in the pointing data from the IMAGE satellite can never be totally ruled out. The latitudinal resolution of the EISCAT data is 0.3-0.8 DEG MLAT. As a consequence, it is unlikely that the difference in OCB proxies can be fully explained by instrumental effects. A possible explanation could be the extension of the electron oval well poleward of the proton oval.

For comparison, a coincidental DMSP-F15 observation was available at 20:50 UT around 09:17 MLT, with an OCB located $\sim 1.1$ DEG MLAT equatorward of the SI12 boundary.

\section{Discussion and conclusions}

We have presented a comparison between the PCB location determined using IMAGE-FUV SI12 and EISCAT radar data, and have compared these also with the MCRB deduced from the MIRACLE magnetometers. We studied three intervals having coincident coverage with these instruments. It is clear that boundaries obtained during a given interval all show the same trend, but the differences can change from one interval to the other. On 7 December 2000, the EISCAT boundary was found several degrees poleward of the SI12 boundary, suggesting electron precipitation poleward of the proton aurora. On 22 September 2001 and 17 February 2002 the average difference between the OCB proxies obtained from EISCAT and SI12 data are within the resolutions of observations, but individual proxies may differ even by several degrees. However, the methods used rely on different measured parameters and work at different spatial scales, so it is perhaps not surprising that they can produce somewhat different boundary locations. The most important result is that both boundaries consistently capture the expected motion of the polar cap during the substorm cycle, which shows that both methods can be used to represent the loading-unloading cycle of the magnetosphere with open 
flux. However, our study indicates a possible dependance on substorm phase. On average, we find that the SI12 PCB is poleward of the EISCAT PCB by roughly 0.4 DEG MLAT during active conditions and when flux closure is on-going, for example during an expansion phase. Prior to flux closure, during a growth phase, for example, the average difference is about -0.83 DEG on average, i.e. the SI12 boundary is found $\sim 0.83$ DEG MLAT equatorward of the EISCAT boundary. When the boundary location is fairly stable, like during a recovery phase, the average difference between the SI12 and EISCAT boundary location that we find largely varies from one interval to the other, from $\sim-0.16$ to $\sim-1.87$ DEG MLAT.

On 17 February 2002, dual-beam EISCAT VHF measurements were made and hence the reconnection electric field could be calculated. The reconnection electric field values were typical of substorm expansion (e.g. Østgaard et al., 2005), and showed large fluctuations with 5 to $8 \mathrm{~min}$ periods (Aikio et al., 2006). The reconnection electric field calculated using the SI12 instrument and SuperDARN data was smaller during a large part of the time interval and lacked similar temporal variations. Two reasons exist for this. Firstly, because there were no SuperDARN data over Scandinavia, the plasma velocity values were instead taken from a model including a combination of statistical data and measured data from SuperDARN radars outside the Scandinavian sector. Secondly, temporal averaging was needed to get the OCB velocity using the SI12 images. The results show the need for high-resolution measurements of the effects of reconnection in the ionosphere.

The OCB proxies were generally located rather close to the polewardmost MCRB. However, one should remember that the ionospheric current reversal boundary may deviate from the MCRB even by several degrees (Amm et al., 2003). In this study we found that in the presence of the Harang discontinuity during substorm periods, the MRCB and the OCB do not agree well. Our results could imply that a part of the substorm-related westward electrojet is located in an open field-line domain. This result needs to be confirmed and studied in more detail in future work. Indeed, the westwarddirected current in the polar cap does not necessarily belong to the westward electrojet.

Acknowledgements. Jean-Claude Gérard and Benoît Hubert are supported by the Belgian Fund for Scientific Research (FRS). This work was funded by the PRODEX program of the European Space Agency (ESA). Work at Leicester was supported by STFC grant PP/D000983/1. EISCAT is an international association supported by China (CRIRP), Finland (SA), Japan (STEL and NIPR), Germany (DFG), Norway (NFR), Sweden (VR) and the United Kingdom (STFC). We thank the institutes who maintain the MIRACLE/IMAGE magnetometer array.

Topical Editor I. A. Daglis thanks P. Newell and G. D. Blanchard for their help in evaluating this paper.

\section{References}

Aikio, A. T., Pitkänen, T., Kozlovsky, A., and Amm, O.: Method to locate the polar cap boundary in the nightside ionosphere and application to a substorm event, Ann. Geophys., 24, 1905-1917, 2006,

http://www.ann-geophys.net/24/1905/2006/.

Aikio, A. T., Pitkänen, T., Fontaine, D., Dandouras, I., Amm, O., Kozlovsky, A., Vaivdas, A., and Fazakerley, A.: EISCAT and Cluster observations in the vicinity of the dynamical polar cap boundary, Ann. Geophys., 26, 87-105, 2008,

http://www.ann-geophys.net/26/87/2008/.

Amm, O., Aikio, A., Bosqued, J.-M., Dunlop, M., Fazakerley, A., Janhunen, P., Kauristie, K., Lester, M., Sillanpää, I., Taylor, M. G. G. T., Vontrat-Reberac, A., Mursula, K., and André, M.: Mesoscale structure of a morning sector ionospheric shear flow region determined by conjugate Cluster II and MIRACLE ground-based observations, Ann. Geophys., 21, 1737-1751, 2003,

http://www.ann-geophys.net/21/1737/2003/.

Blanchard, G. T., Lyons, L. R., Samson, J. C., and Rich, F. J.: Locating the polar cap boundary from observations of $6300 \AA$ auroral emission, J. Geophys. Res., 100, 7855-7862, 1995.

Blanchard, G. T., Lyons, L. R., and Samson, J. T.: Accuracy of using the $6300 \AA$ auroral emission to identify the magnetic separatrix on the nightside of the Earth, J. Geophys. Res., 102, 96979704, 1997a.

Blanchard, G. T., Lyons, L. R., and de la Beaujardière, O.: Magnetotail reconnection rate during magnetospheric substorms, J. Geophys. Res., 102, 24303-24312, 1997b.

Boakes, P. D., Milan, S. E., Abel, G. A., Freeman, M. P., Chisham, G., Hubert, B., and Sotirelis, T.: On the use of IMAGE FUV for estimating the latitude of the open/closed magnetic field line boundary in the ionosphere, Ann. Geophys., 26, 2759-2769, 2008 ,

http://www.ann-geophys.net/26/2759/2008/.

Chisham, G., Freeman, M. P., Coleman, I. J., Pinnock, M., Hairston, M. R., Lester, M., and Sofko, G.: Measuring the dayside reconnection rate during an interval of due northward interplanetary magnetic field, Ann. Geophys., 22, 4243-4258, 2004, http://www.ann-geophys.net/22/4243/2004/.

Chisham, G., Freeman, M. P., Sotirelis, T., Greenwald, R. A., Lester, M., and Villain, J.-P.: A statistical comparison of SuperDARN spectral width boundaries and DMSP particle precipitation boundaries in the morning sector ionosphere, Ann. Geophys., 23, 733-743, 2005,

http://www.ann-geophys.net/23/733/2005/.

Chisham, G., Freeman, M. P., Abel, G. A., Lam, M. M., Pinnock, M., Coleman, I. J., Milan, S. E., Lester, M., Bristow, W. A., Greenwald, R. A., Sofko, G. J., and Villain, J.-P.: Remote sensing the spatial and temporal structure of magnetopause and magnetotail reconnection from the ionosphere, Rev. Geophys., 46, RG1004, doi:10.1029/2007RG000223, 2008.

Grocott, A., Cowley, S. W. H., Sigwarth, J. B., Watermann, J. F., and Yeoman, T. K.: Excitation of twin-vortex flow in the nightside high-latitude ionosphere during an isolated substorm, Ann. Geophys., 20, 1577-1601, 2002,

http://www.ann-geophys.net/20/1577/2002/.

Hubert, B., Milan, S. E., Grocott, A., Blockx, C., Cowley, S. W. H., and Gérard, J.-C.: Dayside and nightside reconnec- 
tion rates inferred from IMAGE FUV and Super Dual Auroral Radar Network data, J. Geophys. Res., 111, A03217, doi:10.1029/2005JA011140, 2006a.

Hubert, B., Palmroth, M., Laitinen, T. V., Janhunen, P., Milan, S. E., Grocott, A., Cowley, S. W. H., Pulkkinen, T., and Gérard, J.-C.: Compression of the Earth's magnetotail by interplanetary shocks directly drives transient magnetic flux closure, Geophys. Res. Lett., 33, L10105, doi:10.1029/2006GL026008, 2006b.

Hubert, B., Kauristie, K., Amm, O., Milan, S. E., Grocott, A., Cowley, S. W. H., Pulkkinen, T. I.: Auroral streamers and magnetic flux closure, Geophys. Res. Lett., 34, L15105, doi:10.1029/2007GL030580, 2007.

Hubert, B., Milan, S. E., Grocott, A., Cowley, S. W. H., and Gérard, J. C.: Open magnetic flux and magnetic flux closure during sawtooth events, Geophys. Res. Lett., 35, L23301, doi:10.1029/2008GL036374, 2008.

Mc Williams, K. A., Pfeiffer J. B., and Mc Pherron, R. L.: Steady magnetospheric convection selection criteria: Implications of global SuperDARN convection measurements, J. Geophys. Res., 35, L09102, doi:10.1029/2008GL033671, 2008.

Mende, S. B., Heetderks, H., Frey, H. U., Lampton, M., Geller, S. P., Habraken, S., Renotte, E., Jamar, C., Rochus, P., Spann, J., Fuselier, S. A., Gérard, J. C., Gladstone, G. R., Murphree, S., and Cogger, L.: Far ultraviolet imaging from the IMAGE spacecraft: 1. System design, Space Sci. Rev., 91, 243-270, 2000a.

Mende, S. B., Heetderks, H., Frey, H. U., Stock, J. M., Lampton, M., Geller, S., Abiad, R., Siegmund, O., Habraken, S., Renotte, E., Jamar, C., Rochus, P., Gérard, J. C., Sigler, R., and Lauche, H.: Far ultraviolet imaging from the IMAGE spacecraft: 3. Spectral imaging of Lyman alpha and OI $135.6 \mathrm{~nm}$, Space Sci. Rev., 91, 287-318, 2000b.

Milan, S. E., Lester, M., Cowley, S. W. H., Oksavik, K., Brittnacher, M., Greenwald, R. A., Sofko, G., and Villain, J.-P.: Variations in the polar cap area during two substorm cycles, Ann. Geophys., 21, 1121-1140, 2003, http://www.ann-geophys.net/21/1121/2003/.

Milan, S. E.: A simple model of the flux content of the distant magnetotail, J. Geophys. Res., 109, A07210, doi:10.1029/2004JA010397, 2004.
Newell, P. T., Wing, S., Meng, C. I., and Sigillito, V.: The auroral oval position, structure and intensity of precipitation from 1984 onward: an automated on-line data base, J. Geophys. Res., 96, 5877-5882, 1991.

Østgaard, N., Moen, J., Mende, S. B., Frey, H. U., Immel, T. J., Gallop, P., Oksavik, K., and Fujimoto, M.: Estimates of magnetotail reconnection rate based on IMAGE FUV and EISCAT measurements, Ann. Geophys., 23, 123-134, 2005, http://www.ann-geophys.net/23/123/2005/.

Pitkänen, T., Aikio, A. T., Kozlovsky, A., and Amm, O.: Reconnection electric field estimates and dynamics of high-latitude boundaries during a substorm, Ann. Geophys., 27, 2157-2171, 2009a, http://www.ann-geophys.net/27/2157/2009/.

Pitkänen, T., Aikio, A. T., Kozlovsky, A., and Amm, O.: Corrigendum to "Reconnection electric field estimates and dynamics of high-latitude boundaries during a substorm" published in Ann. Geophys., 27, 2157-2171, 2009, Ann. Geophys., 27, 3007-3007, 2009b, http://www.ann-geophys.net/27/3007/2009/.

Ruohoniemi, J. M. and Greenwald, R. A.: Statistical patterns of high-latitude convection obtained from Goose Bay HF radar observations, J. Geophys. Res., 101, 21743-21764, 1996.

Ruohoniemi, J. M. and Baker, K. B.: Large scale imaging of high latitude convection with Super Dual Auroral Radar Network HF radar observations, J. Geophys. Res., 103, 20797-20811, 1998.

Sergeev, V. A., Pellinen, R. J., and Pulkkinen, T. I.: Steady magnetospheric convection: a review of recent results, Space Sci. Rev., 75, 551-604, 1996.

Siscoe, G. L. and Huang, T. S.: Polar cap inflation and deflation, J. Geophys. Res., 90, 543-547, 1985.

Wild, J. A., Milan, S. E., Owen, C. J., Bosqued, J. M., Lester, M., Wright, D. M., Frey, H., Carlson, C. W., Fazakerley, A. N., and Rème, H.: The location of the open-closed magnetic field line boundary in the dawn sector auroral ionosphere, Ann. Geophys., 22, 3625-3639, 2004,

http://www.ann-geophys.net/22/3625/2004/. 